\title{
COMPARISON BETWEEN E-TEST AND CLSI BROTH MICRODILUTION METHOD FOR ANTIFUNGAL SUSCEPTIBILITY TESTING OF Candida albicans ORAL ISOLATES
}

\author{
Cristiane Yumi KOGA-ITO(1), Juliana Pereira LYON(2) \& Maria Aparecida de RESENDE(3)
}

\begin{abstract}
SUMMARY
Thirty Candida albicans isolated from oral candidosis patients and 30 C. albicans isolated from control individuals were studied. In vitro susceptibility tests were performed for amphotericin B, fluconazole, 5-flucytosine and itraconazole through the Clinical and Laboratorial Standards Institute (CLSI) reference method and E test system. The results obtained were analyzed and compared. MIC values were similar for the strains isolated from oral candidosis patients and control individuals. The agreement rate for the two methods was $66.67 \%$ for amphotericin B, $53.33 \%$ for fluconazole, $65 \%$ for flucytosine and $45 \%$ for itraconazole. According to our data, E test method could be an alternative to trial routine susceptibility testing due to its simplicity. However, it can not be considered a substitute for the CLSI reference method.
\end{abstract}

KEYWORDS: Candida; NCCLS; E test; Antifungal drugs.

\section{INTRODUCTION}

Candida albicans is a commensal yeast of the normal oral microbiota. However, several local and systemic factors can predispose to the development of oral candidosis. Thus, conditions such as age extremes, immunodeficiency, endocrine disorders, radiotherapy, malignant diseases, xerostomia, denture wearing, poor oral hygiene and orthodontic treatment can be cited as predisposing factors ${ }^{4,12,19,22}$. Nystatin and amphotericin B are common therapeutic agents for oropharyngeal candidosis ${ }^{21}$. The increasing number of clinical isolates resistant to antifungal therapy, as well as the necessity of a guide to the selection and follow-up of the treatment led to a demand for susceptibility testing of fungi ${ }^{13}$. For this purpose, the Clinical and Laboratorial Standards Institute (CLSI) approved a reference method for antifungal susceptibility testing of yeasts, the National Committee for Clinical and Laboratorial Standards (NCCLS) M-27 A2 document ${ }^{14}$. The $\mathrm{E} \mathrm{test}^{1}$ has been introduced as an easier testing procedure and an alternative for the NCCLS method $^{2,6,15,17,20,23}$. The great advantage of $\mathrm{E}$ test is the simplicity of the methodology. However, not all antifungal agents are available in E test and there is a difficulty associated with endpoint interpretation, due to the growth of micro-colonies in the inhibition zone, leading to lower reproducibility when the test is performed by several technicians. The aim of this study was to compare the results of fluconazole, itraconazole, flucytosine and amphotericin B susceptibility testing of $C$. albicans oral strains obtained by the CLSI reference method and the $\mathrm{E}$ test.

\section{MATERIALS AND METHODS}

Isolates: Thirty Candida albicans isolated from denture-associated oral candidosis patients and 30 from control individuals were studied. The patients with candidosis were randomly selected among the patients of the Prosthetics Department of São José dos Campos Faculty of Dentistry (University of the State of São Paulo-UNESP, São Paulo, Brazil). No patient was under treatment with antifungal drugs. The individuals from the control group were randomly selected among students from this University. Patients with basis diseases or smokers or under medication were excluded. The strains were isolated from saliva and identified by biochemical, physiological and morphological tests. Candida spp. strains were transferred onto Sabouraud dextrose agar (Difco Laboratories, Detroit, USA) and stored at $4{ }^{\circ} \mathrm{C}$. C. albicans strains were transferred onto fresh Sabouraud dextrose agar (Difco Laboratories, Detroit, USA) slants 24 hours prior the realization of antifungal susceptibility testing.

Susceptibility testing:

1. NCCLS reference method: The susceptibility assays were determined by the microbroth dilution method performed in sterile flatbottom 96-well microplates (Difco Laboratories, Detroit, USA) as described previously in NCCLS guidelines, M-27 A document (NCCLS, 2002). Briefly, isolates were inoculated at $35^{\circ} \mathrm{C}$ and observed at 24 and 48 hours. Five colonies greater than $1 \mathrm{~mm}$ in diameter were selected, suspended in saline solution and adjusted to a final concentration of 0.5 $\mathrm{x} 10^{3}$ to $2.5 \times 10^{3}$ in RPMI 1640 medium (Sigma, St. Louis, USA) buffered to $\mathrm{pH} 7.0$ with $0.165 \mathrm{M}$ morpholinepropanesulfonic acid (MOPS; Sigma). The antifungal agents fluconazole (Pfizer, São Paulo, Brazil), itraconazole (Janssen Pharmaceutica, São Paulo, Brazil), amphotericin B (Sigma) and flucytosine (5-fluorocytosine; Hoffman La Roche, Basel,

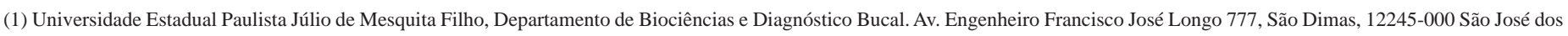
Campos, SP, Brasil.

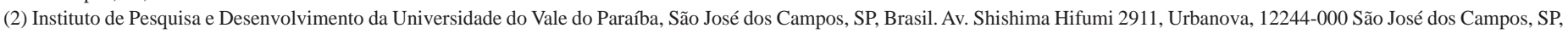
Brasil.

(3) Departamento de Microbiologia, Instituto de Ciências Biológicas, Universidade Federal de Minas Gerais, Brasil. Av. Antonio Carlos 6627, 31270-901 Belo Horizonte, MG, Brasil.

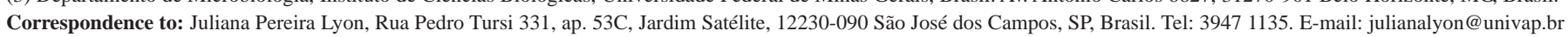


Switzerland) were used in the susceptibility tests. Amphotericin B and itraconazole were dissolved in dimethylsulfoxide. Fluconazole and flucytosine were dissolved in sterile distilled water. The drugs were prepared at the following concentrations: $320 \mu \mathrm{g} / \mathrm{mL}$ for amphotericin B, $1000 \mu \mathrm{g} / \mathrm{mL}$ for flucytosine, $1250 \mu \mathrm{g} / \mathrm{mL}$ for fluconazole and $640 \mu \mathrm{g} /$ $\mathrm{mL}$ for itraconazole. The solutions were diluted in RPMI medium and final drugs concentrations ranged from 32 to $0.04 \mu \mathrm{g} / \mathrm{mL}$ for amphotericin B, 64 to $0.04 \mu \mathrm{g} / \mathrm{mL}$ for itraconazole, 25 to $0.02 \mu \mathrm{g} / \mathrm{mL}$ for flucytosine and 128 to $0.06 \mu \mathrm{g} / \mathrm{mL}$ for fluconazole. After 48 hours of incubation at $35^{\circ} \mathrm{C}$, MIC (minimum inhibitory concentration) was determined visually by comparing its turbidity with the drug-free growth control well. For the azoles and flucytosine the MIC values were defined as the lower drug concentration which resulted in reduction of $80 \%$ in the turbidity in comparison with the drug-free growth control well and for amphotericin $\mathrm{B}$ the MIC value was defined as the lowest drug concentration for which the well was optically clear.

2. E test (AB Biodisk, Solna, Sweden): The E test was performed according to the manufacturer's instructions (AB Biodisk, 1993). In brief, the inoculum concentration was adjusted to 0.5 in McFarland standard for Candida species. Then, $0.5 \mathrm{~mL}$ of this suspension was inoculated onto plates containing RPMI 1640 agar (1.5\%) with 2\% glucose using a cotton swab. After a period of 15 minutes, the E test strips were applied. The antifungal drugs amphotericin B, itraconazole, fluconazole, and flucytosine were tested. The plates were incubated at $35{ }^{\circ} \mathrm{C}$ and read after 24 and 48 hours.

Analysis of the results: The MICs (minimum inhibitory concentration) at which $50 \%\left(\mathrm{MIC}_{50}\right)$ and $90 \%\left(\mathrm{MIC}_{90}\right)$ of the isolates were inhibited were determined for each drug. A comparison between the results obtained by the NCCLS reference method and E test was performed. The rate of agreement was represented as proposed by SEWELL et al. (1994) in terms of percentage of agreement. It was considered agreement when MIC results of E test and NCCLS method were in exact agreement or were within \pm 2 two-fold dilutions. The results were descriptively analyzed.

\section{RESULTS}

The MIC ranges and values of $\mathrm{MIC}_{50}$ and $\mathrm{MIC}_{90}$ obtained for amphotericin B, fluconazole, itraconazole and flucytosine susceptibility testings determined by NCCLS method and E test are summarized in Table 1 and 2, respectively. MIC values were similar for the strains isolated from oral candidosis patients and control individuals.

Table 1

In vitro susceptibility testing of amphotericin B, fluconazole, itraconazole and flucytosine determined by NCCLS reference method

\begin{tabular}{|c|c|c|c|c|c|c|}
\hline \multirow[t]{2}{*}{ Groups } & \multicolumn{2}{|c|}{ MIC ranges $(\mu \mathrm{g} / \mathrm{mL})$} & \multicolumn{2}{|c|}{$\mathrm{MIC}_{50}$} & \multicolumn{2}{|c|}{$\mathrm{MIC}_{90}$} \\
\hline & $24 \mathrm{~h}$ & $48 \mathrm{~h}$ & $24 \mathrm{~h}$ & $48 \mathrm{~h}$ & $24 \mathrm{~h}$ & $48 \mathrm{~h}$ \\
\hline \multicolumn{7}{|l|}{ Control group } \\
\hline Amphotericin B & $0.04-1$ & $0.08-2$ & 0.125 & 0.25 & 1 & 2 \\
\hline Fluconazole & $1-16$ & $1-16$ & 2 & 4 & 8 & 16 \\
\hline Flucytosine & $0.012-0.19$ & $0.012-0.78$ & 0.049 & 0.09 & 0.19 & 0.78 \\
\hline Itraconazole & $0.04-2$ & $0.04-2$ & 0.25 & 0.5 & 1 & 4 \\
\hline \multicolumn{7}{|l|}{ Candidosis group } \\
\hline Amphotericin B & $0.08-2$ & $0.08-2$ & 0.5 & 1 & 4 & 8 \\
\hline Fluconazole & $0.5-16$ & $0.5-16$ & 2 & 8 & 32 & 64 \\
\hline Flucytosine & $0.012-0.39$ & $0.012-0.39$ & 0.049 & 0.19 & 0.19 & 0.78 \\
\hline Itraconazole & $0.125-4$ & $0.125-4$ & 0.5 & 2 & 4 & 16 \\
\hline
\end{tabular}

MIC - minimum inhibitory concentration

Table 2

In vitro susceptibility testing of amphotericin B, fluconazole, itraconazole and flucytosine determined by E test.

\begin{tabular}{|c|c|c|c|c|c|c|}
\hline \multirow[t]{2}{*}{ Groups } & \multicolumn{2}{|c|}{ MIC ranges $(\mu \mathrm{g} / \mathrm{mL})$} & \multicolumn{2}{|c|}{$\mathrm{MIC}_{50}$} & \multicolumn{2}{|c|}{$\mathrm{MIC}_{90}$} \\
\hline & $24 \mathrm{~h}$ & $48 \mathrm{~h}$ & $24 \mathrm{~h}$ & $48 \mathrm{~h}$ & $24 \mathrm{~h}$ & $48 \mathrm{~h}$ \\
\hline \multicolumn{7}{|l|}{ Control group } \\
\hline Amphotericin B & $<0.03-0.75$ & $<0.03-0.75$ & 0.125 & 0.5 & 1 & 2 \\
\hline Fluconazole & $0.125->256$ & $0.023->256$ & 0.5 & 0.5 & 1 & 1 \\
\hline Flucytosine & $0.003->32$ & $0.006->32$ & 0.023 & 0.032 & 0.125 & 0.125 \\
\hline Itraconazole & $0.006-24$ & $0.006->32$ & 0.047 & 0.064 & 0.5 & 0.5 \\
\hline \multicolumn{7}{|l|}{ Candidosis group } \\
\hline Amphotericin B & $0.094-0.5$ & $0.094-0.5$ & 0.25 & 0.5 & 0.5 & 0.5 \\
\hline Fluconazole & $0.064-16$ & $0.064-16$ & 0.25 & 0.25 & 0.75 & 0.75 \\
\hline Flucytosine & $0.003-32$ & $0.003->32$ & 0.023 & 0.023 & 0.032 & 0.047 \\
\hline Itraconazole & $0.016->32$ & $0.016->32$ & 0.064 & 0.064 & 0.25 & 0.75 \\
\hline
\end{tabular}

MIC - minimum inhibitory concentration 
Table 3

Percentage of agreement (exact agreement or within \pm 2 two-fold dilutions) between the MIC (minimum inhibitory concentration) values obtained by NCCLS method and E test

\begin{tabular}{lcc}
\hline Antifungal drug & \multicolumn{2}{c}{ Percentage of agreement } \\
& $24 \mathrm{~h}$ & $48 \mathrm{~h}$ \\
\hline Amphotericin B & & \\
- control group & $50 \%$ & $73.33 \%$ \\
- candidosis group & $83.33 \%$ & $70 \%$ \\
Average & $\mathbf{6 6 . 6 7 \%}$ & $\mathbf{7 1 . 6 7 \%}$ \\
\hline Fluconazole & & \\
- control group & $53.33 \%$ & $1.67 \%$ \\
- candidosis group & $53.33 \%$ & $1 \%$ \\
Average & $\mathbf{5 3 . 3 3 \%}$ & $\mathbf{1 . 3 4 \%}$ \\
\hline Flucytosine & & \\
- control group & $83.33 \%$ & $50 \%$ \\
- candidosis group & $46.67 \%$ & $36.66 \%$ \\
Average & $\mathbf{6 5 \%}$ & $\mathbf{4 3 . 3 3 \%}$ \\
\hline Itraconazole & & \\
- control group & $40 \%$ & $33 \%$ \\
- candidosis group & $50 \%$ & $36.66 \%$ \\
Average & $\mathbf{4 5 \%}$ & $\mathbf{3 4 . 8 3 \%}$ \\
\hline
\end{tabular}

The comparison of the MICs values obtained by NCCLS reference method and $\mathrm{E}$ test at $24 \mathrm{~h}$ and $48 \mathrm{~h}$ were compared and the percentages of agreement are presented in Table 3 .

\section{DISCUSSION}

The comparison between E test and CLSI methodology has been studied by several authors. Earlier studies related a good agreement between the NCCLS reference microdilution method and the E test for the azoles susceptibility testing. In these researches, the agreement percentages varied from 71 to $85.2 \%$ for ketoconazole ${ }^{6,9}$, from 80 to $96 \%$ to fluconazole $e^{7,20,23}$ and from 80 to $84 \%$ for itraconazole. However, in more recent publications, authors related poorer agreement percentages between these two susceptibility testing methods. KOC et $a l .{ }^{9}$ and MARTIN-MAZUELOS ${ }^{11}$ related percentages of $74-79 \%$ for fluconazole. For itraconazole, MARTIN-MAZUELOS ${ }^{11}$ obtained $61.4 \%$ of agreement.

In the present study, poor agreement was observed for fluconazole (53.33\%) and itraconazole (45\%) at 24 hours. Additionally, agreement observed at 48 hours was even worst. ESPINEL-INGROFF ${ }^{7}$ also related a poorer agreement after 48 hours of incubation in comparison with results observed in 24 hours.

The determination of the endpoints for the azoles is a significant factor in the variability of MIC results. The partial growth inhibition makes it difficult to determine MIC values accurately ${ }^{3,18}$. The same person always performed the interpretation of MIC results in the CLSI method. Similarly, to avoid variability in endpoint readings due to the difficulty in define the borders of inhibition zone in the E test method, the same person scored all the plates.
PFALLER et al. ${ }^{16}$ obtained the best agreement between the NCCLS reference method and the E test using the RPMI agar with $2 \%$ glucose. For this reason, all E test experiments were performed with this type of medium.

For amphotericin B susceptibility testing, good correlation was observed between the tested methods at 24h (66.67\%) and 48 hours. Interestingly, best agreement percentage was observed after 48 hours (71.67\%). VAN ELDERE et al. ${ }^{23}$ and KOC et al. ${ }^{9}$ also related good agreement rates that varied from 90 to $96 \%$.

For flucytosine, a good agreement between the NCCLS method and $\mathrm{E}$ test was observed at 24 hours (65\%). These results are in accordance to those obtained by CHANG et al. ${ }^{5}$ and ISHIGAKI et al. ${ }^{8}$. At 48 hours, a moderated correlation could be observed (43.33\%).

The present study demonstrated a lower percentage of agreement between the methodologies tested than other studies found in literature. The discrepancy might be due to interlaboratory differences or to the use of different media for E test methodology. This fact reinforces the importance of tests standardization. On the other hand, it is relevant to notice that the evaluator was not blind regarding the test or for the antifungal agent evaluated, which might be considered a limitation of the present work.

Minimmum inhibitory concentrations obtained in the present study were similar for control samples and samples obtained from candidosis patients. A higher MIC could possibly be expected for candidosis patients, since virulence factors such as exoenzyme production have been correlated with antifungal resistance ${ }^{10}$.

In conclusion, E test method could be considered an alternative to trial routine susceptibility testing due to its simplicity. However, it can not be considered, at this moment, a substitute for NCCLS reference method, since a complete agreement between both methodologies has not been reached, as demonstrated by the present study and corroborated by others presented in literature. Due to the numerous variables associated to the E test method, further studies must be performed to standardize the medium and incubation conditions. Moreover, studies on the correlation of in vitro antifungal susceptibility testing and clinical response to these drugs are essentially important.

\section{RESUMO}

\section{Comparação entre E-test e o método da microdiluição do CLSI para teste de susceptibilidade a antifúngicos de isolados orais de Candida albicans}

Trinta Candida albicans isoladas de pacientes portadores de candidose oral e 30 Candida albicans isoladas de indivíduos controle foram estudadas. Testes de susceptibilidade in vitro foram realizados com anfotericina B, fluconazol, 5-flucitosina e itraconazol pelo método do Clinical and Laboratorial Standars Institute (CLSI) e por E-test. Os resultados obtidos foram analisados e comparados. Os valores de CIM foram semelhantes para amostras isoladas de pacientes portadores de candidose oral e indivíduos controle. A concordância entre os dois métodos foi de $66,7 \%$ para a anfotericina B, 53,33\% para o fluconazol, $65 \%$ para a flucitosina e $45 \%$ para o itraconazol. De acordo com estes 
resultados, o método do E-test poderia ser uma alternativa para a triagem de casos de rotina pela sua simplicidade. Entretanto, este método não pode ser considerado como um substituto para o método de referência do CLSI.

\section{ACKNOWLEDGEMENTS}

This study was supported by FAPEMIG (Fundação de Amparo à Pesquisa do Estado de Minas Gerais).

\section{REFERENCES}

1. AB BIODISK - Antifungal susceptibility testing of yeasts. Solna, AB BIODISK, 1993. (E-test Technical Guide, No. 4).

2. AMBLER, J.E.; KERAWALA, M.; YANEZA, A. \& DRABU, Y.J. -Evaluation of CHROMagar Candida for rapid identification and Etest for antifungal susceptibility testing in a district hospital laboratory. J. clin. Path., 54: 158-159, 2001.

3. ARENDRUP, M.; LUNDGREN, B.; JENSEN, I.M.; HANSEN, B.S. \& FRIMODTMOLLER, N. - Comparison of Etest and a tablet diffusion test with the NCCLS broth microdilution method for fluconazole and amphotericin B susceptibility testing of Candida isolates. J. Antimicrob. Chemother., 47: 521-526, 2001.

4. BUDTZ-JÖRGENSEN, E. - Etiology, pathogenesis, therapy and prophylaxis of yeast infection. Acta odontol. scand., 48: 61-69, 1990.

5. CHANG, H.C.; CHANG, J.J.; CHAN, S.H. et al. - Evaluation of Etest for direct antifungal susceptibility testing of yeasts in positive blood cultures. J. clin. Microbiol., 39: 1328-1333, 2001.

6. COLOMBO, A.L.; BARCHIESI, F.; McGOUGH, D.A. \& RINALDI, M.G. - Comparison of Etest and National Committee for Clinical Laboratory Standards broth macrodilution method for azole antifungal susceptibility testing. J. clin. Microbiol., 33: 535-540, 1995.

7. ESPINEL-INGROFF, A.; PFALLER, M.; ERWIN, M.E. \& JONES, R.N. - Interlaborarory evaluation of Etest method for testing antifungal susceptibilities of pathogenic yeasts to five antifungal agents by using Casitone agar and solidified RPMI 1640 medium with 2\% glucose. J. clin. Microbiol., 34: 848-852, 1996.

8. ISHIGAKI, S.; KAWAKAMI, S.; ONO, Y. \& MIYAZAWA, Y. - Evaluation of a new method for antifungal drugs susceptibility testing to yeasts. Kansenshogaku Zasshi, 74: 221-230, 2000.

9. KOC, A.N.; GOKAHMETOGLU, S. \& OGUZKAYA, M. - Comparison of Etest with the broth microdilution method in susceptibility testing of yeasts isolates against four antifungal. Mycoses, 43: 293-297, 2000.

10. LYON, J.P. \& RESENDE, M.A. - Correlation between adhesion, enzyme production, and susceptibility to fluconazole in Candida albicans obtained from denture wearers. Oral Surg. oral Med. oral Path. oral Radiol. Endod., 102: 632-638, 2006.

11. MARTIN-MAZUELOS, E.; GUTIERREZ, M.J.; ALLER, A.I. et al. - A comparative evaluation of Etest and broth microdilution methods for fluconazole and itraconazole susceptibility testing of Candida spp. J. Antimicrob. Chemother., 43: 477-481, 1999.
12. MAZA, J.L.; ELGUEZABAL, N.; PRADO, C. et al. - Candida albicans adherence to resin-composites restorative dental materials: influence of role human saliva. Oral Surg. oral Med. oral Path. oral Radiol. Endod., 94: 589-592, 2002.

13. MONTEIL, R.A.; MADINIER, I. \& LE FICHOUX, Y. - In vitro antifungal resistance of oral Candida albicans strains in non-AIDS patients. Oral Microbiol. Immunol., 12: 126-128, 1997.

14. NATIONAL COMMITTEE FOR CLINICAL LABORATORY STANDARDS Reference method for broth dilution antifungal susceptibility testing of yeasts. Approved standard M27-A2. Villanova, National Committee for Clinical Laboratory Standards, 2002.

15. PFALLER, M.A.; MESSER, S.A. \& COFFMAN, S. - Comparison of visual and spectrophotometric methods of MIC endopoint determinations by using broth microdilution methods to test five antifungal agents, including the new triazone D0870. J. clin. Microbiol., 33: 1094-1097, 1995.

16. PFALLER, M.A.; MESSER, S.A. \& BOLMSTRÖM, A. - Evaluation of Etest for determining in vitro susceptibility of yeast isolates to amphotericin B. Diagn. Microbiol. infect. Dis., 32: 223-227, 1998.

17. PFALLER, M.A.; MESSER, S.A.; HOUSTON, A. et al. - Evaluation of the Etest method for determining voriconazole susceptibilities of 312 clinical isolates of Candida species by using three different agar media. J. clin. Microbiol., 38: 3715-3717, 2000.

18. REX, J.H.; PFALLER, M.A.; RINALDI, M.G.; POLAK, A. \& GALGIANI, J.N. Antifungal susceptibility testing. Clin. Microbiol. Rev., 6: 367-381, 1993.

19. RUISSEN, A.L.A.; GROENINK, J.; LOMMERSE, C.H. et al. - Effect of carbohydrate polymers applicable in saliva substitutes on the anti-Candida activity of a histatinderived peptide. Arch. oral Biol., 47: 749-756, 2002.

20. SEWELL, D.L.; PFALLER, M.A. \& BARRY, A.L. - Comparison of broth macrodilution, both microdilution and E test antifungal susceptibitlity tests for fluconazole. J. clin. Microbiol., 32: 2099-2102, 1994.

21. SHU, M.; ELLEPOLA, A.N.B. \& SAMARANAYAKE, L.P. - Effects of two different growth media on the postantifungal effect induced by polyenes on Candida species. J. clin. Microbiol., 39: 2732-2735, 2001.

22. TORRES, S.R.; PEIXOTO, C.B.; CALDAS, D.M. et al. - Relationship between salivary flow rates and Candida counts in subjects with xerostomia. Oral Surg. oral Med. oral Path. oral Radiol. Endod., 93: 149-154, 2002.

23. VAN ELDERE, J.; JOOSTEN, L.; VERHAEGHE, V. \& SURMONT, I. - Fluconazole and amphotericin B antifungal susceptibility testing by National Committee for Clinical Laboratory Standards broth macrodilution method compared with E-test and semiautomated broth microdilution test. J. clin. Microbiol., 34: 842-847, 1996.

Received: 15 December 2006 Accepted: 24 September 2007 